\title{
KEMANDIRIAN BELAJAR MAHASISWA MELALUI BLENDED LEARNING PADA MATA KULIAH MATEMATIKA EKONOMI
}

\author{
Rahmi Wahyuni ${ }^{1}$, Nurhayati ${ }^{1}$ \\ ${ }^{1}$ Universitas Al-Muslim, J1 Tengku Abdurrahman No 37 Matangglumpangdua Bireuen, 24261, Indonesia \\ Email: rahmirusli@gmail.com \\ Email: nurhayati09.nur@gmail.com
}

\begin{abstract}
Abstrak
Matematika Ekonomi merupakan salah satu matakuliah wajib dari prodi pendidikan Matematikan Universitas Al-muslim. Penelitian ini bertujuan untuk mengetahui respon mahasiswa terhadap kemandirian belajar melalui blended learning pada mata kuliah matematika ekonomi. Penelitian ini menggunakan metode kualitatif karena data diperoleh dari para narasumber khususnya para siswa dengan metode yang lebih alamiah, yaitu mengobservasi langsung dan pembagian angket sehingga dapat mengambil suatu kesimpulan terhadap yang diteliti. Angket yang digunakan merujuk pada skala liked dengan pilihan untuk responden adalah sangat setuju, setuju, tidak setuju, dan sangat tidak setuju. Jumlah pertanyaan ada 15 pertanyaan dengan kesemuanya adalah pertanyaan positif. Berdasarkan hasil analisis data maka dapat disimpulkan bahwa, tanggapan responden terhadap kemandirian belajar mahasiswa melalui pembelajaran blanded learning pada mata kuliah matematika ekonomi sebesar $77 \%$ dari hasil tersebut maka tanggapan responden berada pada kriteria baik karena $77 \%$ ada pada rentang 68.01-84.00
\end{abstract}

Kata Kunci: Kemandirian Belajar, Blended Learning, Matematika Ekonomi

\begin{abstract}
Mathematical Economics is one of the compulsory subjects of the Mathematics Education study program at the University of Almuslim. This study aims to determine the response of students to learning independence through blended learning in mathematics economics courses. This study uses a qualitative method because the data is obtained from the resource persons, especially students, with a more natural method, which is directly observing and distributing questionnaires so that they can draw a conclusion on the study. The questionnaire used refers to the scale liked by the choice for respondents is strongly agree, agree, disagree, and strongly disagree. There are 15 questions with all positive questions. Based on the results of data analysis, it can be concluded that, respondents 'responses to the independence of student learning through blanded learning in economics mathematics courses amounted to $77 \%$ of the results, the respondents' responses were in good criteria because $77 \%$ were ranked $68.01-84.00$
\end{abstract}

Keywords: Independence of Learning, Blended Learning, Mathematical Economics

\section{PENDAHULUAN}

Self-regulated learning (kemandirian belajar) atau sering disingkat dengan SRL yang sebenarnya sudah dikenal sejak tahun 1980an, yaitu sejak disadari pentingnya menanamkan tanggungjawab pada siswa atas proses belajarnya sendiri. Didefinisikan oleh beberapa ahli antaranya, menurut Schunk dan Zimmerman (dalam Sumarmo, 2010) didefinisikan sebagai proses belajar yang terjadi karena pengaruh dari pemikiran, perasaan, strategi, dan perilaku sendiri yang berorientasi pada pencapaian tujuan. Menurut Pintrich (dalam Tjall, 2008) Self Regulated Learning adalah cara belajar siswa aktif secara individu untuk mencapai tujuan akademik dengan cara pengontrolan perilaku, memotivasi diri sendiri dan menggunakan kognitifnya dalam belajar. Dan menurut Hargis (dalam Sumarmo, 2010) SRL itu sendiri bukan merupakan kemampuan mental atau keterampilan akademik tertentu seperti kefasihan membaca, namun merupakan proses pengarahan 
diri dalam mentransformasi kemampuan mental ke dalam keterampilan akademik tertentu. Seorang peserta didik dikatakan mempunyai kemandirian belajar apabila ia mempunyai keinginan sendiri untuk belajar, menyelesaikan masalah, dan bertanggung jawab dalam menyelesaikan kewajibannya. sebagai peserta didik. Namun kenyataannya kemandirian belajar mahasiswa sekarang ini sangatlah kurang. Hal ini didasarkan pada penelitian Nursa'ban (2013) yang menunjukkan bahwa pada siklus pertama rata-rata kemandirian belajar mahasiswa hanya sebesar 47. Menurut Zumbrunn (2011) guru/dosen sebaiknya melaksanakan proses pembelajaran yang dapat memfasilitasi muridnya agar memiliki kemandirian belajar. Ini berarti bahwa dosen hendaknya mendesain suatu pembelajaran yang dapat membuat mahasiswa menjadi mandiri dalam belajar.

Salah satu pembelajaran yang dapat meningkatkan kemandirian belajar mahasiswa adalah blended learning Menurut Izzudin (Saihaan, 2013) blended learning adalah pembelajaran yang menggabungkan pembelajaran secara tatap muka (face to face learning) dan secara virtual (elearning). Pernyataan ini sejalan dengan temuan penelitian Sari (2013) yang menyimpulkan bahwa strategi blended learning berhasil meningkatkan kemandirian belajar sebesar $72,8 \%$. Selain itu Sutisna (2016) dari hasil penelitiannya juga menyimpulkan bahwa model pembelajaran blended learning efektif untuk meningkatkan kemandirian belajar peserta didik. Jika kita lihat beberapa penelitian di atas, dapat disimpulkan bahwa blended learning mampu meningkatkan kemandirian belajar mahasiswa karena e-learning merupakan perpanjangan dari ruang kelas yang bisa diakses oleh mahasiswa dimana saja. Oleh karena itu, tujuan dari penelitian ini adalah untuk melihat respon siswa terhadap kemandirian belajar melalui pembelajaran blended learning pada matakuliah matematika ekonomi.

Woolfolk (wahyuni, 2013) menyatakan bahwa faktor-faktor yang mempengaruhi kemandirian belajar meliputi : pengetahuan (knowledge), motivasi (motivation) dan disiplin pribadi (selfdiscipline). Paris dan Winograd (dalam Tim Penatar Undiksha, 2007) menyebutkan beberapa ciri dari siswa yang memiliki SRL, yaitu:

a) Kesadaraan tentang pikiran, yaitu kesadaran siswa tentang: (i) kebiasaan berfikirnya, dan (ii) bagaimana berfikir yang efektif; dengan kata lain, siswa harus bisa berfikir tentang bagaimana pikiran bekerja. Ini merupakan aspek metakognisi, yang dapat berwujud evaluasi diri dan pengelolaan diri.

b) Penggunaan strategi belajar, dimana Paris dan Winograd menekankan dua hal, yaitu: (i) strategi yang digunakan dan (ii) menjadi orang yang strategis. Seperti diketahui, terdapat tiga aspek metakognisi, yaitu: pengetahuan deklaratif (pengetahuan tentang strategi), pengetahuan procedural (pengetahuan tentang bagaimana melakukan strategi tersebut), dan pengetahuan kondisional (pengetahuan tentang kapan dan bagaimana suatu strategi harus dilakukan). Ketiga pengetahuan ini bila dimiliki oleh siswa, dapat membantu mereka berfikir strategis dan memilih strategi yang paling tepat untuk memecahkan suatu masalah.

c) Motivasi yang terpelihara, yaitu dorongan secara terus-menerus untuk melakukan suatu hal dan mencapai hasil yang tinggi dari usaha yang dilakukan. Guru perlu merangsang timbulnya motivasi pada siswa dan tetap memeliharanya karena perannya yang sangat penting dalam proses belajar siswa.

Beberapa indikator untuk mengukur kemandirian belajar peserta didik yang diuraikan oleh Sumarmo (2010) yaitu: (1) inisiatif belajar; (2) mendiagnosa kebutuhan belajar; (3) menetapkan target atau tujuan belajar; (4) memonitor, mengatur dan mengontrol; (5) memandang kesulitan sebagai tantangan; (6) memanfaatkan dan mencari sumber yang relevan; (7) memilih dan menerapkan strategi belajar; (8) mengevaluasi proses dan hasil belajar; (9) self efficacy (konsep diri).

Whitelock dan Jelfs (2003) memberikan beberapa definisi mengenai blended learning, yaitu (1) kombinasi antara pembelajaran tradisional dengan pendekatan pembelajaran berbasis web, (2) kombinasi dari media dan tools dalam lingkungan e-learning, (3) kombinasi dari beberapa pendekatan pembelajaran, penggunaan teknologi pembelajaran. Dari beberapa definisi tersebut, dapat disimpulkan 
bahwa blended learning merupakan pembelajaran yang menggabungkan pembelajaran tatap muka (face to face) dan pembelajaran berbasis internet (e-learning). Melalui e-learning mahasiswa dilatih untuk belajar mandiri. Mahasiswa bisa memperkuat pengetahuannya dengan cara mencari sendiri pengetahuan yang mereka butuhkan melalui fasilitas internet dengan arahan dosen. Dengan memanfaatkan fasilitas internet, mahasiswa dapat mengakses sumber belajar dimana saja dan kapan saja. Walaupun demikian, pertemuan secara tatap muka juga diperlukan agar lebih mendekatkan dosen dengan mahasiswa. Selain itu, pemantauan terhadap respon mahasiswa juga dapat diamati dan diberikan umpan balik.

\section{METODE PENELITIAN}

Penelitian ini menggunakan metode kualitatif karena data diperoleh dari para narasumber khususnya para siswa dengan metode yang lebih alamiah, yaitu mengobservasi langsung dan pembagian angket sehingga dapat mengambil suatu kesimpulan terhadap yang diteliti. Penelitian ini dilaksanakan di Universitas Almuslim dengan subjek penelitian adalah mahasiswa pendidikan matematika semester V tahun akademik 2019/2020.

Pengolahan data angket respon siswa secara rinci melalui beberapa tahapan sebagai berikut: (a) Pengecekan tarhadap kelengkapan jumlah angket dan kesesuaian antara angket yang disebarkan dengan data yang berhasil terkumpul kembali; (b) Penyeleksian angket yang memenuhi syarat adalah angket yang seluruh pertanyaaan dijawab oleh responden sesuai dengan petunjuk yang telah ditentukan; (c) Penskoran (Arikunto, 2006). Memberi skor pada setiap pernyataan dengan menggunakan skala likert.

Data penelitian yang diperoleh dari hasil pemeriksaan angket, selanjutnya diolah berdasarkan teknik pengolahan yang telah ditetapkan sebelumnya. Pengolahan data dalam penelitian ini dilakukan dengan langkah sebagai berikut :

a) Menetapkan angket yang telah diolah, yaitu angket yang memenuhi kriteria yang ditetapkan dalam pemeriksaan angket.

b) Menetapkan kualifikasi alternatif jawaban setiap item angket yaitu jawaban dengan kualifikasi sangat setuju, diberi bobot 4 , kualifikasi setuju diberi bobot 3, kualifikasi tidak setuju diberi bobot 2, dan kualifikasi sangat tidak setuju diberi bobot 1 .

c) Melakukan pengolahan angket.

d) Menetapkan tolak ukur untuk kategori hasil perhitungan persentase sebagai pedoman interpretasi data yang telah diperoleh dari perhitungan persentase.

Untuk setiap butir pernyataan positif dengan kategori sangat setuju (SS), setuju (S), tidak setuju (TS), dan sangat tidak setuju (STS) masing-masing diberi skor berturut-turut 4,3,2,1; (d) Penetuan kriteria respon berdasarkan rentangan $80-100 \%$ (sangat baik); 60-80\% (baik); 40-60\% (cukup baik); $20-40 \%$ (kurang baik), 0-20\% (sangat tidak baik) dengan rumus sebagai berikut:

$P x=\frac{\text { Banyaknya Siswa yang Memberi Respon }}{\text { Jumlah Seluruh Siswa yang Memberi Respon }} \times 100 \%$

Keterangan:

$P x=\%$ siswa yang memberi respon

$x=$ respon sangat positif, positif, negatif, atau sangat negatif.

Respon terhadap kemandirian belajar dengan pembelajaran blanded learning berdasarkan jawaban respon dapat menggunakan rumus sebagai berikut:

$$
\% \text { skor aktual }=\frac{\text { skor aktual }}{\text { skor } \text { ideal }} \times 100 \%
$$


Keterangan :

1. Skor aktual adalah jawaban seluruh responden atas kuesioner yang telah dianjurkan

2. Skor ideal adalah nilai tertinggi atau semua responden diasumsikan memilih jawaban dengan skor tertinggi

Tabel kriteria persentase skor tanggapan terhadap skor ideal yang di sajikan dalam tabel berikut :

Tabel 1. Kriteria Persentase Skor Tanggapan Terhadap Skor Ideal

\begin{tabular}{|l|l|l|}
\hline No & \% Jumlah Skor & Kriteria \\
\hline 1 & $20.00-36.00$ & Tidak Baik \\
\hline 2 & $36.01-52.00$ & Kurang Baik \\
\hline 3 & $52.01-68.00$ & Cukup \\
\hline 4 & $68.01-84.00$ & Baik \\
\hline 5 & $84.02-100$ & Sangat Baik \\
\hline
\end{tabular}

\section{HASIL PENELITIAN DAN PEMBAHASAN}

Hasil analisis data berikut memperlihatkan persentase jawaban dari responden untuk tiap indikator berdasarkan kriteria respon mulai dari sangat setuju, setuju, tdak setuju dan sangat tidak setuju.

Tabel 2. Indikator Kemandirian Belajar Mahasiswa

\begin{tabular}{|c|l|c|c|c|c|}
\hline \multirow{2}{*}{ No } & \multicolumn{2}{|c|}{ Indikator Kemandirian Belajar } & \multicolumn{3}{c|}{ \% Kriteria Respon } \\
\cline { 3 - 5 } & SS & S & TS & STS \\
\hline 1 & $\begin{array}{l}\text { Akses komunikasi dosen dan teman di kelas Elearning } \\
\text { tanpa di batasi oleh jarah, ruang dan waktu }\end{array}$ & $63 \%$ & $38 \%$ & $0 \%$ & $0 \%$ \\
\hline 2 & $\begin{array}{l}\text { Pembelajaran online Elearning membuat saya tidak } \\
\text { bergantung pada orang lain }\end{array}$ & $38 \%$ & $50 \%$ & $13 \%$ & $0 \%$ \\
\hline 3 & Saya belajar sesuai dengan jadwal & $25 \%$ & $50 \%$ & $25 \%$ & $0 \%$ \\
\hline 4 & $\begin{array}{l}\text { Fitur pada media elearning dapat menyimpan bahan } \\
\text { ajar sehingga mudah untuk saya akses kapan saja }\end{array}$ & $50 \%$ & $50 \%$ & $0 \%$ & $0 \%$ \\
\hline 5 & $\begin{array}{l}\text { Pembelajaran elearning membuat saya aktif dalam } \\
\text { mencari tugas yang harus dikerjakan }\end{array}$ & $13 \%$ & $50 \%$ & $25 \%$ & $13 \%$ \\
\hline 6 & $\begin{array}{l}\text { Pembelajaran Elearning membuat saya mandiri dalam } \\
\text { memecahkan soal yang harus dikerjakan }\end{array}$ & $13 \%$ & $50 \%$ & $38 \%$ & $0 \%$ \\
\hline 7 & $\begin{array}{l}\text { Pembelajaran Elearning membuat saya tidak menunda } \\
\text { mengerjakan tugas }\end{array}$ & $25 \%$ & $38 \%$ & $25 \%$ & $13 \%$ \\
\hline 8 & $\begin{array}{l}\text { Pembelajaran Elearning membuat saya mengumpulkan } \\
\text { tugas dengan tepat waktu }\end{array}$ & $88 \%$ & $13 \%$ & $0 \%$ & $0 \%$ \\
\hline 9 & $\begin{array}{l}\text { Motivasi belajar saya bertambah dengan pembelajaran } \\
\text { elearning }\end{array}$ & $25 \%$ & $63 \%$ & $13 \%$ & $0 \%$ \\
\hline 10 & Saya mengulang kembali materi di rumah & $25 \%$ & $50 \%$ & $25 \%$ & $0 \%$ \\
\hline 11 & $\begin{array}{l}\text { Saya mengulang kembali tes/ ulangan untuk dikerjakan } \\
\text { di rumah }\end{array}$ & $13 \%$ & $38 \%$ & $38 \%$ & $13 \%$ \\
\hline 12 & \begin{tabular}{l} 
Saya belajar berani mengemukakan pendapat dalam \\
\hline
\end{tabular} & $25 \%$ & $38 \%$ & $25 \%$ & $13 \%$ \\
\hline
\end{tabular}




\begin{tabular}{|c|l|c|c|c|c|}
\hline & pembelajaran & & & & \\
\hline 13 & Saya percaya pada kemampuan diri sendiri & $38 \%$ & $50 \%$ & $13 \%$ & $0 \%$ \\
\hline 14 & $\begin{array}{l}\text { Saya belajar sendiri tanpa diperintah oleh orang tua } \\
\text { atau saudara }\end{array}$ & $25 \%$ & $38 \%$ & $25 \%$ & $13 \%$ \\
\hline 15 & $\begin{array}{l}\text { Pembelajaran Elearning membuat suasana belajar saya } \\
\text { lebih tenang dan nyaman }\end{array}$ & $38 \%$ & $50 \%$ & $13 \%$ & $0 \%$ \\
\hline & Rata-rata & $33 \%$ & $44 \%$ & $18 \%$ & $4 \%$ \\
\hline
\end{tabular}

Berdasarkan tabel datas terlihat bahwa persentase jawaban dar responden untuk setuju dan sangat setuju lebih besar dari pada plihan jawaban tdak setuju dan sangat tidak setuju. Karena seluruh pertanyaan dari angket kemandiran belajar adalah pertanyaan postif maka hal ini menunjukkan hal yang positif. Untuk rata-rata yang menjawab sangat setuju adalah $33 \%$ dan rata-rata yang menjawab setuju adalah $44 \%$. Berdasarkan data dari tabel tersebut, maka data tabel disajikan kedalam diagram batang yang disajikan sebagai berikut:

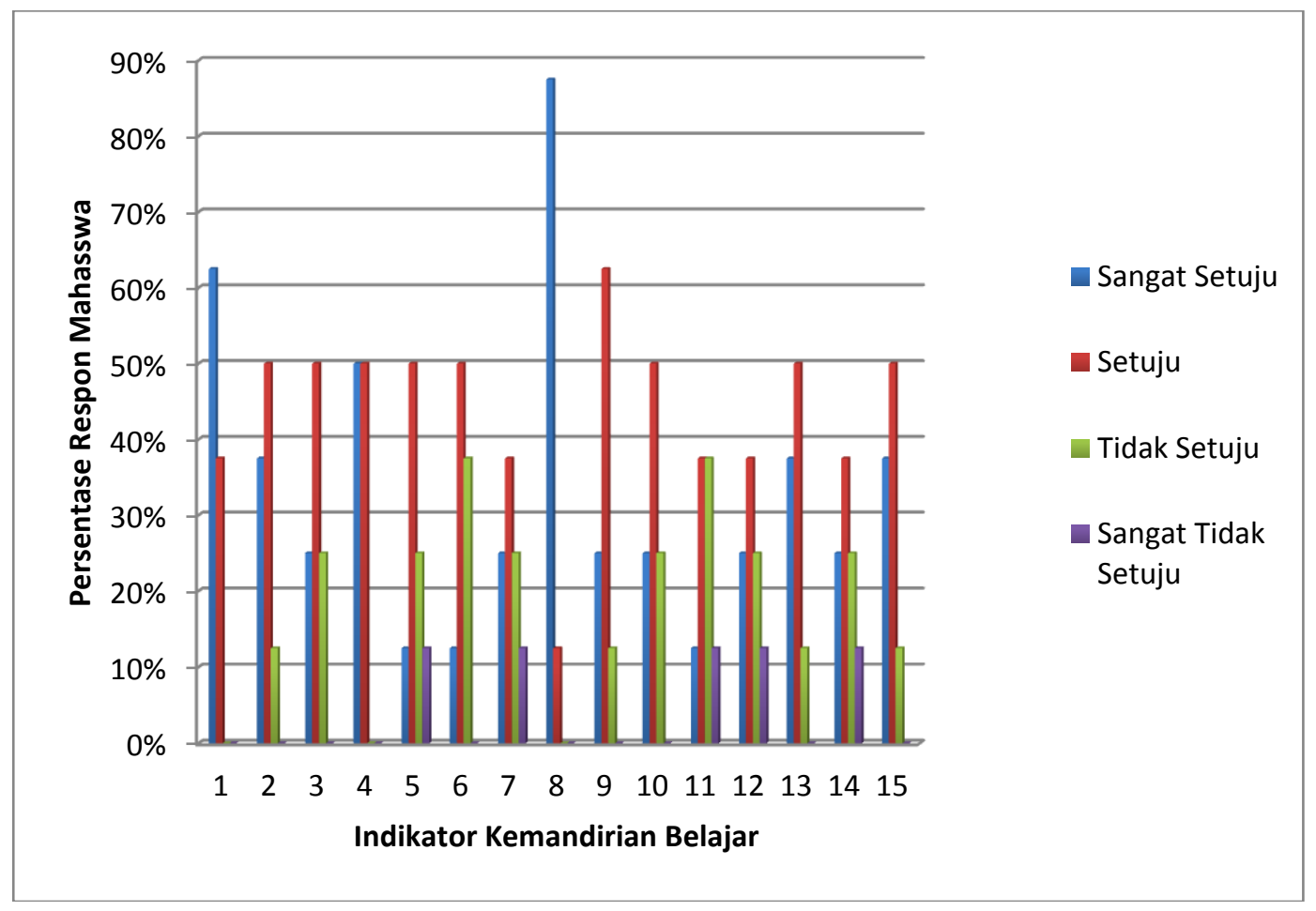

Gambar 1. Grafik Data Angket Respon Mahasiswa

Dari gambar diatas terlihat bahwa persentase responden untuk sangat setuju dan setuju tinggi dari pada responden yang melilih tidak setuju dan sangat tidak setuju.

Selain melihat persentase tanggapan dari responden berdasarkan pemilihan jawaban juga dianalsis untuk persentase skor aktualnya. Dimana skor actual di bagi dengan skor ideal dikali 100\%. Berikut data tanggapan responden terhadap kemandirian belajar dengan skor actual dan skor ideal. 
Tabel 3. Tanggapan Responden terhadap Kemandirian Belajar

\begin{tabular}{|c|c|c|c|c|c|c|c|c|c|c|c|c|c|c|c|c|}
\hline Total & \multicolumn{10}{|c|}{ Instrumen } & Total \\
\cline { 2 - 15 } & 1 & 2 & 3 & 4 & 5 & 6 & 7 & 8 & 9 & 10 & 11 & 12 & 13 & 14 & 15 & \\
\hline $\begin{array}{c}\text { Skor } \\
\text { aktual }\end{array}$ & 29 & 26 & 24 & 28 & 21 & 22 & 22 & 31 & 25 & 24 & 20 & 22 & 26 & 22 & 26 & 368 \\
\hline $\begin{array}{c}\text { Skor } \\
\text { Ideal }\end{array}$ & 32 & 32 & 32 & 32 & 32 & 32 & 32 & 32 & 32 & 32 & 32 & 32 & 32 & 32 & 32 & 480 \\
\hline
\end{tabular}

$\%$ skor aktual $=\frac{\text { skor aktual }}{\text { skor } \text { ideal }} \times 100 \%$

$\%$ skor aktual $=\frac{368}{480} \times 100 \%=77 \%$

Berdasarkan perhitungan diatas, maka dapat disimpulkan bahwa tanggapan responden terhadap kemandirian belajar mahasiswa melalui pembelajaran blanded learning adalah sebesar $77 \%$ dari hasil tersebut maka tanggapan responden adalah berada pada kriteria baik karena $77 \%$ ada pada rentan 68.01-84.00

\section{KESIMPULAN}

Berdasarkan hasil penelitian dan analisis data angket respon mahasiswa menunjukkan bahwa mahasiswa memiliki kemandirian belajar yang tinggi dengan menggunakan pembelajaran blanded learning. Pertanyaan yang diajukan dalam bentuk pertanyaan positif. Tanggapan responden terhadap kemandirian belajar mahasiswa melalui pembelajaran blanded learning pada mata kulah matematika ekonom sebesar 77\% dari hasil tersebut maka tanggapan responden berada pada kriteria baik.

\section{REFERENCES}

Arikunto, Suharsimi. (2006). Dasar- Dasar Evaluasi Pendidikan. Jakarta: Bumi Aksara.

Saihaan, S. (2013). E-Learning (Pembelajarn Elektronik) Sebagai Salah Satu Alternatif Kegiatan Pembelajaran. Jurnal Pendidikan dan Kebudayaan. No. 042. Tahun ke 9. Mei 2013.

Sari, A. R. (2013). Strategi Blended Learning untuk Peningkatan Kemandirian Belajar dan Kemampuan Critical Thinking Mahasiswa di Era Digital. Jurnal Pendidikan Akuntansi Indonesia, XI(2): 32-43.

Sumarmo, Utari.(2010).Kemandirian belajar: Apa, Mengapa, dan Bagaimana Dikembangkan Pada Peserta Didik. Tersedia http://math.sps.upi.edu/?p=61. (Diakses 1 November 2019).

Syah, Muhibbin. (2011). Psikologi Belajar. Jakarta: PT Raja Grafindo Persada.

Wahyuni, Rahmi. (2013). Peningkatan Kemampuan Pemecahan Masalah Matematis dan Kemandirian Belajar Siswa Melalui Penerapan Model Pembelajaran Kooperatif Tipe Think Pair Share (TPS).Tesis. UNIMED

Zumbrunn, et al. (2011). Encouraging Self-Regulated Learning in the Zlassroom: A Review of the Literature. Metropolitan Educational Research Consortium (MERC), Virginia Commonwealth University. 